\title{
Perinatal behavior of a wild Grevy's zebra (Equus grevyi) mare and foal
}

\author{
Blair A. Roberts
}

\begin{abstract}
This paper describes the postpartum behavior of a wild Grevy's zebra (Equus grevyi) mare and foal. The foal first attempted to stand within 5 min of birth and succeeded at approximately $10 \mathrm{~min}$ after birth. Within $40 \mathrm{~min}$ of birth, the infant could walk steadily. The foal did not suckle during the observation time. An ethogram of observed behaviors is provided.
\end{abstract}

Keywords Birth · Postpartum behavior - Grevy's zebra . Equus grevyi $\cdot$ Equid

\section{Introduction}

For many mammalian species, the behavior of mother and young immediately after birth can strongly affect the survival of both individuals and the development of the neonate (Le Bouef et al. 1972; Nowak et al. 2000; Ozoga et al. 1982; Townshend and Bailey 1975). It is during this time that the first socialization of the young takes place and the motherinfant bond is formed (Collias 1956). Rapid attainment of mobility is often crucial to the ability of the neonate to feed or avoid predation. Risk of predation and injury tends to be elevated during the early postpartum period due to the young's helplessness and lack of coordination and the mother's exhaustion from labor (Estes and Estes 1979).

Maternal care strategy and social structure, among other factors, can affect the challenges mothers and neonates face after parturition and the strategies they employ to

B. A. Roberts $(\bowtie)$

Department of Ecology and Evolutionary Biology,

Princeton University, 106A Guyot Hall,

Princeton, NJ 08544, USA

e-mail: barobert@Princeton.edu overcome such obstacles. Grevy's zebra (Equus grevyi) is an African equid species. Like all equids, Grevy's zebra exhibits a follower-type maternal care strategy in which the young accompanies the mother after birth rather than concealing itself in vegetation (Lent 1974; Walther 1965). Socially, Grevy's zebra is similar to wild and domestic ass species in that males typically defend territories through which females roam rather than forming harems like those exhibited by horses and other zebra species (Kimura 2000; Klingel 1974, 1998).

Grevy's zebra is an endangered species with a large portion $(\sim 20 \%)$ of the remaining individuals held in captivity in zoos and sanctuaries (Williams 2002). No account of the perinatal behavior of this species exists from wild or captive populations. Accounts of such behavior in other wild equid species are scarce. This is due to the rare and unpredictable nature of births and to the secretive behavior of parturient females (Fraser 1968). Additionally, equids may be able to delay parturition by several hours if they are disturbed in the early phases of labor (Campitelli et al. 1982; Klingel 1969; Rossdale 1968). As such, current knowledge of parturition and perinatal behavior in equids is based largely on observations of captive individuals and domestic species (Lickliter 1984). Descriptions of these behaviors in wild equids are therefore crucial to the understanding of natural parturient behavior.

I present here observations of Grevy's zebra perinatal behavior collected during an opportunistic encounter with a parturient mother.

\section{Study area}

The observation took place between 4:00 and 5:00 pm on 24 June 2009 on Mpala Ranch $\left(36^{\circ} 52^{\prime} \mathrm{E}, 0^{\circ} 17^{\prime} \mathrm{N}\right)$ in 
Laikipia, Kenya. Parturition occurred in an area of black cotton soil and Acacia drepanolobium woodland.

\section{Materials and methods}

I observed all events from a vehicle. Observations began when I spotted the mother in the second stage of labor and ended when the adults and neonate moved out of sight into dense bush. Observations were interrupted once for less than 10 min after the initial sighting when the mother moved deeper into the trees, requiring that I reposition the vehicle. I took care to ensure that the vehicle remained as far from the birth site as possible while still affording a clear view in order to minimize disturbance to the mother and foal. The distance between the vehicle and the zebras varied between approximately 60 and $100 \mathrm{~m}$. Times of behaviors were obtained from timestamps of photographs taken during the observation.

\section{Results and discussion}

I spotted one adult male and two adult female Grevy's zebras at approximately 4:15 pm. One female was lying down when the vehicle approached but stood when the car stopped. She was in the second phase of labor (Fraser 1968) with the hooves and legs of a foal protruding approximately $30 \mathrm{~cm}$ from her vagina. The zebras moved out of sight into the acacias, and I repositioned the vehicle. At 4:24 pm I resighted the mare. She had completed parturition and was sternally recumbent next to the foal, whose back and hindquarters were still encased in the amnion (Fig. 1). The other two group members stood some $50 \mathrm{~m}$ away, grazing and periodically looking toward the

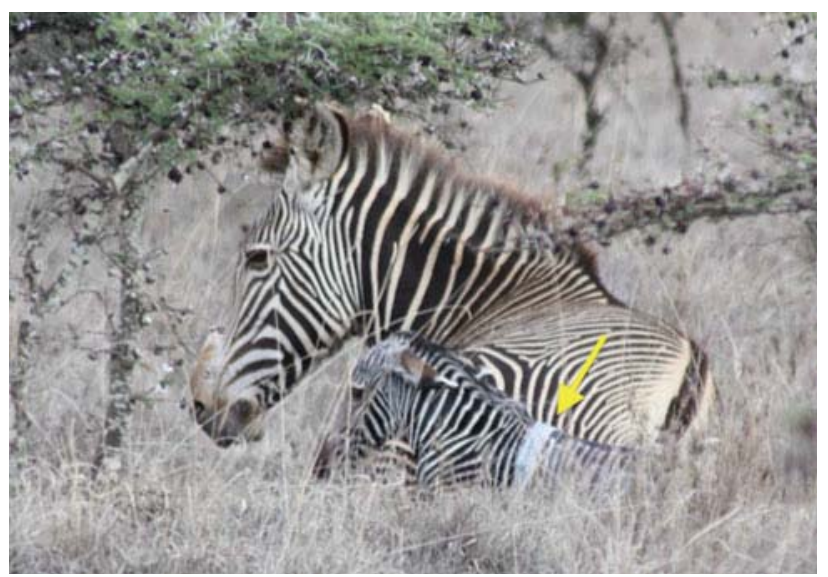

Fig. 1 Mare and neonate immediately after parturition. The amnion (indicated by arrow) is visible on the foal's back mother. I estimate the birth to have occurred at approximately 4:20 pm.

The foal first attempted to stand up at 4:25 pm, but was unsuccessful and fell back to the ground. The mare stood up at 4:28 pm and expelled the afterbirth. She did not attempt to help the foal stand, nor did she lick the foal or consume the afterbirth or amnion. The foal continued its attempts to stand and was successful at 4:34 pm (Fig. 2). At 4:35 it attempted to walk but was hindered by the attached umbilical cord and placenta. By 4:36 the foal managed to take several steps, dragging the placenta by the umbilicus (Fig. 3). At this point the male and other female began to move away from the mare and my vehicle. The mare attempted to lead the foal after the rest of the group by walking away from and then looking back at the infant (Fig. 4). The foal followed for a few steps and then stopped. The mother periodically snorted, which seemed to call the infant's attention to her. The foal attempted to follow her, but was still unable to walk steadily enough. When the mare moved beyond a certain distance from the infant, the foal stopped moving toward its mother and began moving towards my vehicle. At this point, the mother moved toward the foal and snorted to call it back. By 4:48, the infant's movements had severed the umbilical cord. The mother continued her attempts to lead the foal off, and at 5:07 pm, when the infant could walk steadily, the entire group moved out of sight together. The foal did not suckle or attempt to suckle from the mother during my observations.

Table 1 presents an ethogram of behaviors noted during this observation. All of these behaviors except "induce following" have been reported in parturition accounts for other equid species (Blakeslee 1974; Boyd 1980, 1988; Campitelli et al. 1982; Jeffcott 1972; Klingel 1969; McCort 1980; Rossdale 1967, 1968; Tyler 1972;

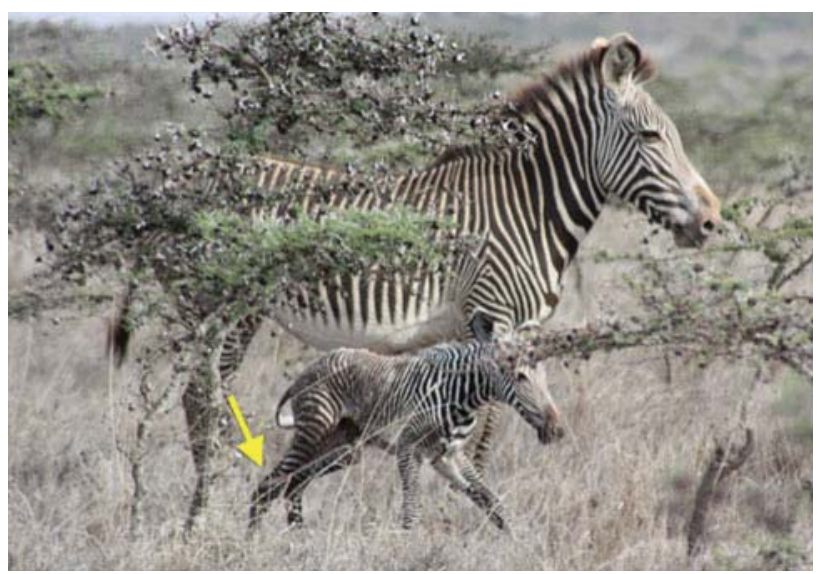

Fig. 2 Foal standing successfully. The umbilicus (indicated by arrow) is still attached and visible, wrapped around the foal's right hind leg just above the hock 


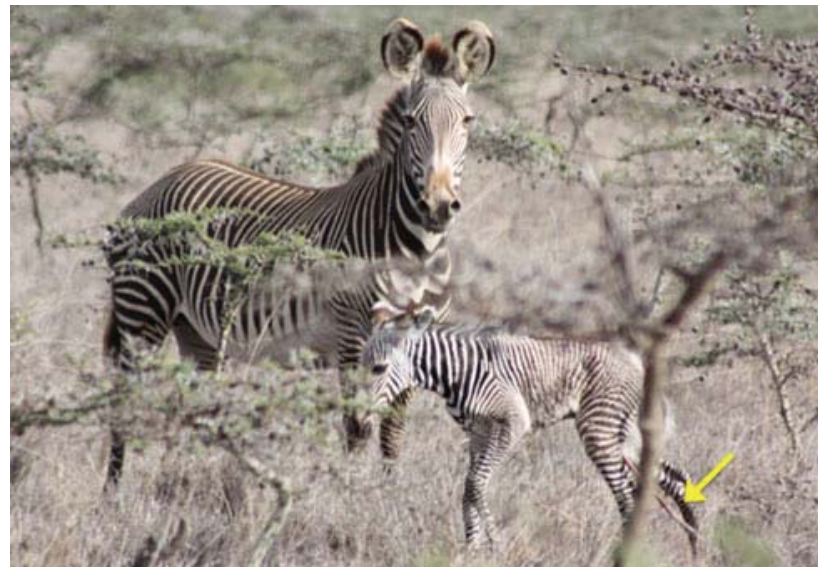

Fig. 3 Foal walking and dragging the placenta by the umbilicus (indicated by arrow)

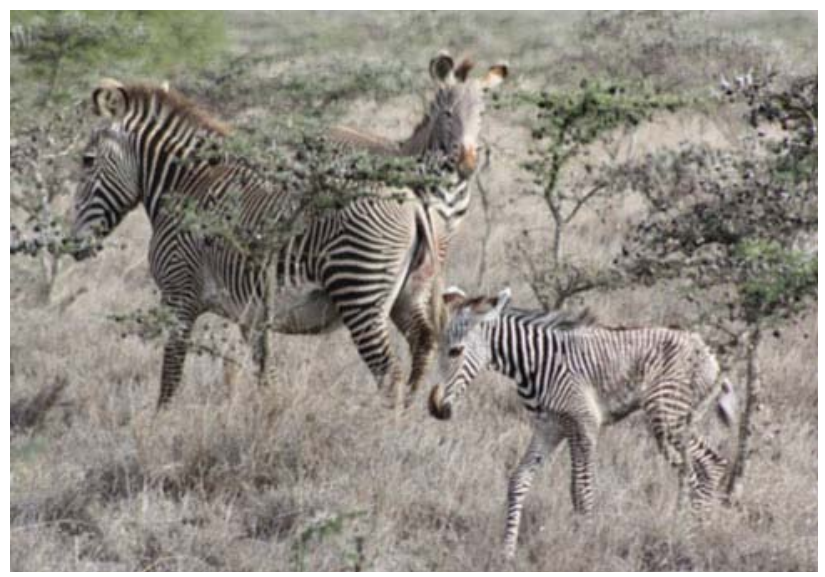

Fig. 4 Mare attempting to lead the foal toward the departing group members
Wackernagel 1965; Waring 1982). The timing of these behaviors in Grevy's zebra is comparable to those reported for other equid species. The mare and foal stood, the foal first attempted to stand, and the placenta was expelled within or near the range of times reported for other equid species. However, the umbilical cord broke later than in other equid species, and the foal attempted to walk and succeeded earlier.

The umbilicus was severed 28 min postpartum (mpp) compared with 8-15 mpp in other equid species (Blakeslee 1974; Boyd 1988; Klingel 1969; Rossdale 1967, 1968). The cord broke later because it remained intact after the mare stood up, whereas this action broke the cord in most other accounts. The apparent precocity of the Grevy's zebra foal in attempting to walk (at $15 \mathrm{mpp}$ compared with 20-40 mpp in other equids; Boyd 1980, 1988) and succeeding (at $47 \mathrm{mpp}$, compared with 68-74 mpp in other equids; Waring 1982) is likely a product of a lack of data. These behaviors are rarely reported for other equids, thus the timing recorded here may prove to be within the normal range of equids if more data are collected.

In addition to these disparities, it is atypical in equids for the mare to not isolate for birth and to not lick the foal. Mothers of most equid species isolate before birth in order to avoid harassment of the neonate by conspecifics, which can cause injury to the foal or disruption of the motherinfant bond necessary for parental care (Blakeslee 1974; Boyd 1980, 1988; Fischhoff et al. 2010; McCort 1980; Sundaresan et al. 2007; Tyler 1972). However, neither accompanying zebra approached the mare or her foal during my observation. Possibly, Grevy's zebras do not isolate because conspecifics do not tend to interfere during the perinatal period.

Table 1 Ethogram of postnatal behaviors of Grevy's zebra mares and neonates and the time at which the behaviors occurred in this observation

\begin{tabular}{lll}
\hline Behavior & Description & Time (min after birth) \\
\hline $\begin{array}{l}\text { Mare behaviors } \\
\text { Stand }\end{array}$ & Mother stands after parturition \\
$\begin{array}{l}\text { Expel placenta } \\
\text { Induce following }\end{array}$ & $\begin{array}{l}\text { The placenta is expelled from the mother's vagina } \\
\text { Mother encourages foal to follow as she walks away. May include snorting, }\end{array}$ & 8 \\
glancing back at foal, and returning to foal if it ceases to follow & 16 \\
Foal behaviors & & 5 \\
Attempt to stand & Foal attempts to rise from a recumbent position but falls before standing & 14 \\
Stand & Foal rises from a recumbent position and stands still on all four legs for at least 1s & 15 \\
Attempt to walk & Foal attempts to walk but falls before taking one step with each foot & 16 \\
Walk & Foal takes one step with each foot without falling down & Not recorded \\
Follow & Foal walks towards the mare as she walks away from the foal & 28 \\
Other behaviors & & Umbilical cord ruptures (usually due to the mare standing up or the foal's movements) \\
Sever umbilicus & & 28 \\
\hline
\end{tabular}


Although equid mothers usually do not consume the placenta and birth tissues, most do engage in intense and prolonged licking of the foal (Blakeslee 1974; Boyd 1980, 1988; Jeffcott 1972; McCort 1980; Tyler 1972). However, the Grevy's zebra mare did not lick her foal, and plains zebras lick only superficially if at all (Klingel 1969; Wackernagel 1965). Licking is proposed to stimulate the neonate to move and encourage maternal behavior, bonding, and recognition of the foal through olfactory and gustatory stimuli present in the birth tissues (Lent 1974; Levy and Poindron 1987). Why licking should be prominent in some equid species but not others is not clear.

Finally, the timing of the birth in the late afternoon appears maladaptive (Estes and Estes 1979; Tyler 1972). Morning is thought to be the ideal time for ungulates to give birth as this allows maximum time for the mother and young to bond and for the neonate to become steady on its feet before nightfall (Tyler 1972). Morning parturition seems especially advantageous for free-ranging African ungulates given that most major African predators are nocturnal (Estes and Estes 1979). Many of these species, including lions, hyenas, wild dogs, and leopards, are present at Mpala Ranch and pose a threat to Grevy's zebra foals. It seems plausible, therefore, that the timing of the observed birth may put the foal at an increased risk of predation.

Births are rare, rapid events that are difficult to predict and observe in wild animals. Therefore, bodies of data on parturition and perinatal behavior in natural settings must be obtained piecemeal through fortuitous observations such as the one reported here (Fraser 1968). Additional instances of Grevy's zebra perinatal behavior must be documented before any conclusions can be drawn about the behavioral patterns of parturient mothers and neonates of this species. It is hoped that the ethogram provided here can be expanded and used in future observations to build a consistent database of Grevy's zebra and equid perinatal behavior.

Acknowledgments I thank the Ministry of Education, Government of Kenya for allowing me to work in Kenya, and Mpala Ranch and its administration and staff for permitting me to work on the premises and for supporting me in the field. I also wish to thank John Kitoe for his assistance and guidance in the field, Elaine Bigelow for sharing her photos for reference for this paper, and Cassandra Nuñez, Siva Sundaresan, and Michael Costelloe for their advice and edits. This paper was made possible by funding from Princeton University's Department of Ecology and Evolutionary Biology and from my graduate advisor, Dr. Daniel Rubenstein.

\section{References}

Blakeslee JK (1974) Mother-young relationships and related behavior among free-ranging appaloosa horses. MSc Thesis, Idaho State University, Pocatello
Boyd LE (1980) The natality, foal survivorship, and mare-foal behavior of feral horses in Wyoming's Red Desert. MSc Thesis, University of Wyoming, Laramie

Boyd LE (1988) Ontogeny of behavior in Przewalski horses. Appl Anim Behav Sci 21:41-69

Campitelli S, Carenzi C, Verga M (1982) Factors which influence parturition in the mare and development of the foal. Appl Anim Ethol 9:7-14

Collias NE (1956) The analysis of socialization in sheep and goats. Ecology 37:228-239

Estes RD, Estes RK (1979) The birth and survival of wildebeest calves. Z Tierpscyhol 50:45-95

Fischhoff IR, Sundaresan SR, Larkin HM, Sellier M-J, Cordingley JE, Rubenstein DI (2010) A rare fight in female plans zebra. J Ethol 28:201-205

Fraser AF (1968) Reproductive behaviour in ungulates. Academic, London

Jeffcott LB (1972) Observations on parturition in crossbred pony mares. Equine Vet J 4:209-214

Kimura R (2000) Relationship of the type of social organization to scent-marking and mutual-grooming behaviour in Grevy's (Equus grevyi) and Grant's zebras (Equus burchelli bohmi). J Equine Sci 11:91-98

Klingel H (1969) Reproduction in the plains zebra, Equus burchelli boehmi: behaviour and ecological factors. J Reprod Fertil Suppl 6:339-345

Klingel H (1974) A comparison of the social behaviour of the Equidae. In: Geist V, Walther F (eds) The behaviour of ungulates and its relation to management. IUCN, Morges, pp 124-132

Klingel H (1998) Observations on social organization and behaviour of African and Asiatic wild asses (Equus africanus and Equus hemionus). Appl Anim Behav Sci 60:103-113

Le Bouef BJ, Whiting RJ, Gantt RF (1972) Perinatal behavior of Northern elephant seal females and their young. Behaviour 43:121-156

Lent PC (1974) Mother-infant relationships in ungulates. In: Geist V, Walther F (eds) The behaviour of ungulates and its relation to management. IUCN, Morges, pp 14-55

Levy F, Poindron P (1987) The importance of amniotic fluids for the establishment of maternal behaviour in experienced and inexperienced ewes. Anim Behav 35:1188-1192

Lickliter RE (1984) Behavior associated with parturition in the domestic goat. Appl Anim Behav Sci 13:335-345

McCort WD (1980) The behavior and social organization of feral asses (Equus asinus) on Ossabaw Island, Georgia. PhD Thesis, Pennsylvania State University, University Park

Nowak R, Porter RH, Lévy F, Orgeur P (2000) Role of mother-young interactions in the survival of offspring in domestic mammals. Rev Reprod 5:153-163

Ozoga JJ, Verme LJ, Bienz CS (1982) Parturition behavior and territoriality in white-tailed deer: impact on neonatal mortality. J Wildlife Manage 46:1-11

Rossdale PD (1967) Clinical studies on the newborn thoroughbred foal. Br Vet J 123:470-481

Rossdale PD (1968) Perinatal behavior in the thoroughbred horse. In: Fox MW (ed) Abnormal behavior in animals. Saunders, Philadelphia, pp 227-237

Sundaresan SR, Fischhoff IR, Rubenstein DI (2007) Male harassment influences female movements and associations in Grevy's zebra (Equus grevyi). Behav Ecol 18:860-865

Townshend TW, Bailey ED (1975) Parturitional, early maternal, and neonatal behavior in penned white-tailed deer. J Mammal $56: 347-362$

Tyler SJ (1972) The behaviour and social organization of the New Forest ponies. Anim Behav Monogr 5:87-196 
Wackernagel H (1965) Grant's zebra, Equus burchelli boehmi, at Basle Zoo-a contribution to breeding ecology. Int Zoo Yearb 5:38-41

Walther F (1965) Verhaltensstudien an der Gattung Tragelaphus de Blainville (1816) in Gefangenschaft unter besonderer Berucksichtigung des Sozialverhaltens. 21:393-467
Waring GH (1982) Onset of behaviour patterns in the newborn foal. Equine Pract 4:28-31, 34

Williams SD (2002) Status and action plan for Grévy's zebra (Equus grevyi). In: Moehlman PD (ed) Equids: zebras, asses, and horses: status survey and conservation action plan. IUCN/SSC Equid Specialist Group, Gland, pp 11-27 